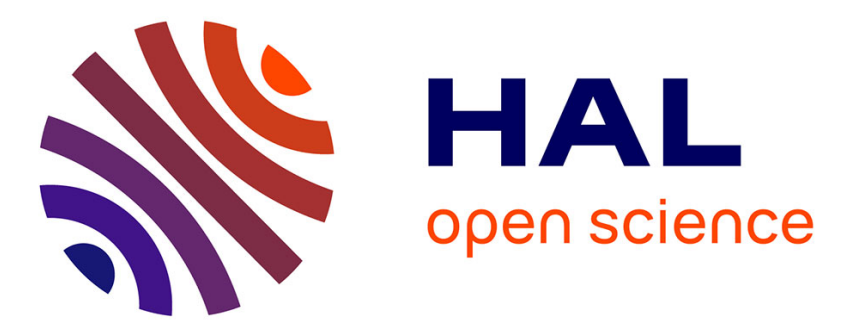

\title{
Fracture behavior of robocast HA/beta-TCP scaffolds studied by X-ray tomography and finite element modeling
}

Clemence Petit, Sylvain Meille, Eric Maire, Laurent Gremillard, Jérôme Adrien, Grace Y. Lau, Antoni P. Tomsia

\section{To cite this version:}

Clemence Petit, Sylvain Meille, Eric Maire, Laurent Gremillard, Jérôme Adrien, et al.. Fracture behavior of robocast HA/beta-TCP scaffolds studied by X-ray tomography and finite element modeling. Journal of the European Ceramic Society, 2017, 37 (4), pp.1735-1745. 10.1016/j.jeurceramsoc.2016.11.035 . hal-01814369

\section{HAL Id: hal-01814369 \\ https://hal.science/hal-01814369}

Submitted on 24 Aug 2018

HAL is a multi-disciplinary open access archive for the deposit and dissemination of scientific research documents, whether they are published or not. The documents may come from teaching and research institutions in France or abroad, or from public or private research centers.
L'archive ouverte pluridisciplinaire HAL, est destinée au dépôt et à la diffusion de documents scientifiques de niveau recherche, publiés ou non, émanant des établissements d'enseignement et de recherche français ou étrangers, des laboratoires publics ou privés. 


\title{
Fracture behavior of robocast HA/ $\beta$-TCP scaffolds studied by X-ray tomography and finite element modeling
}

\author{
Published in Journal of the european ceramic society (2017), 37 (4) pp. 1735-45 \\ http://dx.doi.org/10.1016/j.jeurceramsoc.2016.11.035
}

Clémence Petit $^{1}$, Sylvain Meille ${ }^{1}$, Eric Maire ${ }^{1}$, Laurent Gremillard ${ }^{1}$, Jérôme Adrien ${ }^{1}$, Grace Y. $\mathrm{Lau}^{2}$, and Antoni P. Tomsia ${ }^{2}$

${ }^{1}$ Univ Lyon, INSA Lyon, MATEIS CNRS UMR5510, F-69621 VILLEURBANNE, France

${ }^{2}$ Materials Sciences Division, Lawrence Berkeley National Laboratory

1 Cyclotron Road, Berkeley, CA 94720, USA

Corresponding author: sylvain.meille@insa-lyon.fr

\begin{abstract}
Hydroxyapatite (HA)/ $\beta$-tricalcium phosphate $(\beta$-TCP) cellular composites were fabricated by robocasting. Small polymeric beads were intentionally added into the solid rods of the samples to generate artificial defects in order to characterize their influence on the fracture behavior in uniaxial compression. The samples were characterized by X-ray tomography at two resolutions to observe their architectural and microstructural features. The higher resolution images were obtained by "local tomography" in which the sample is placed near the X-ray source. These images allowed for observing details (i.e., the artificial defects) not visible at a lower resolution. Then ex situ compression tests were performed to follow the deformation of the sample at low resolution by tomography. The images showed a brittle-like behavior with the propagation of a main crack parallel to the compression direction. Finally, the high-resolution images of the initial sample were processed to create a finite element (FE) model of the whole sample and including the presence of artificial defects in the struts. The $e x$ situ test and the modeling show the influence of the artificial defects on the crack initiation.
\end{abstract}

Keywords: Calcium phosphate, porous ceramics, X-ray tomography, mechanical behavior, finite element modeling

\section{Introduction}

Calcium phosphate ceramics, especially hydroxyapatite (HA) and $\beta$-tricalcium phosphate ( $\beta$ TCP) have been widely used for bone substitution $[1,2,3,4]$ because they exhibit a unique combination of properties: biocompatibility, osteoconductivity, osteointegration, bioresorption, and bioactivity [5]. HA/ $\beta$-TCP composites (commonly named biphasic calcium phosphates [BCP]) have been developed [6] with the aim of optimizing material in terms of mechanical properties and resorption in the human body. An interconnected porosity is necessary to promote bone regeneration and vascularization around and inside the scaffolds, as well as to allow circulation of fluids in the scaffold. Several studies have shown that scaffolds need interconnected macropores with a size higher than $100 \mu \mathrm{m}$ and micropores with a size between 10 and $100 \mu \mathrm{m}$ to improve bone regeneration $[7,8,9,10]$.

Various fabrication techniques have been used to fabricate porous calcium phosphate samples: the replica technique [11], sacrificial templates [12], and direct foaming [13]. Additive 
manufacturing (AM) has gained interest because it can provide samples with complex shapes and an intricate internal architecture, allowing control of mechanical properties [14, 15]. Among the AM techniques available to process ceramics, robocasting is a robotic deposition of a ceramic ink (viscous slurry) through a nozzle following a computer-aided model. Robocasting can be distinguished from the other AM processes by the use of aqueous ceramic inks with a low amount of organic additives (typically less than 1wt\%) [16, 17]. The inks are also highly viscous thus with a high solid loading. These features facilitate the densification during the heat treatment. The ceramic ink has to flow through the nozzle during the extrusion step and set after deposition [17]. The ink's characteristics (e.g. high solid loading, concentration of organic additives such as dispersant) must be carefully controlled to avoid some specific defects. For example, if the solid loading is too low, the shrinkage will be too important during drying and cracks will appear [17, 18]. After deposition, there is also a risk of bending of the rods [19]. A too high solid loading will impose a high pressure for extrusion. This can cause an inhomogeneous re-distribution of liquid and ceramic particles into the ink $[18,20]$. Thus the solid loading will be different throughout the structure. Thus, several studies have been dedicated to the optimization of this fabrication process for ceramics and the formulation of ceramic inks [16, 17, 21]. For example, Houmard et al. [22] fabricated BCP samples with a wide range of volume fraction and pore size. Other authors focused more on the mechanical properties of scaffolds processed by robocasting, such as Miranda et al., who reported the propagation of long cracks along the compression direction for HA and $\beta$ TCP samples [23, 24].

The aim of this research is to perform a fundamental and qualitative study of the fracture process in uniaxial compression of BCP scaffolds by means of X-ray tomography. This nondestructive technique provides three-dimensional (3D) images of the samples. It has been extensively used to characterize highly porous materials [25]. In or ex situ mechanical tests can also be performed by adding special rigs inside the tomograph. We have recently used this approach to characterize the uniaxial compression behavior of a porous $\beta$-TCP sample with a stochastic porosity generated by a sacrificial template method [26]. Additionally, the tomographic images can be used as input files for finite element (FE) modeling [27]. Meshing the 3D images allows performing calculations based on the real architecture of the specimens. In the present study, porous BCP samples were processed via robocasting and scanned by Xray tomography. Model materials were designed by adding artificial defects in the struts thanks to pore formers. Our aim was to generate defects having a controlled size in the structure. The location of these defects in the initial microstructure was determined by highresolution scans obtained with the so-called "local tomography" mode. Then an ex situ compression test was performed to follow the crack propagation by standard low resolution $\mathrm{X}$-ray tomography. Finally, high-resolution images of the initial samples were processed to create an FE model and to check the influence of artificial defects in the struts on the mechanical behavior of the scaffolds.

\section{Materials and methods}

\subsection{Sample fabrication}

Cellular samples with a solid phase containing a volume fraction of $80 \%$ HA and $20 \% \beta$-TCP were fabricated following a protocol thoroughly described by Miranda et al. [28]. A 20 vol.\% Pluronic F127 solution in water was prepared and cooled to approximately $4^{\circ} \mathrm{C}$. Adequate quantities of HA (Science Applications Industries, France) and of $\beta$-TCP (Fluka, Switzerland) were mixed with this solution to form an aqueous paste with a solid loading of $30 \mathrm{vol} . \%$, fluid at low temperature and solid at room temperature thanks to the addition of Pluronic. Two 
vol.\% of polymethacrylate (PMMA) spheres (Diakon CLG356, Lucite International, France) were added as porogens to create artificial defects inside the solid struts. The PMMA beads were previously sieved and the spheres with a diameter from 45 to $100 \mu \mathrm{m}$ were selected. This particular size range was chosen because it allows having controlled defects in the rods which can be detected by X-ray tomography with resolution of few microns, as used in this work. This size range can also be distinguished from the residual micropores with a size of few microns $[19,23]$. The ceramic ink and the PMMA beads were mixed in a jar. The mixture of ceramic ink and PMMA beads was introduced in the conical nozzle of the robocasting device (3-D Inks, Stillwater, USA) controlled by a software program (Robocad 3.0, 3-D Inks, Stillwater, USA). The nozzle had a diameter of $150 \mu \mathrm{m}$ and was displaced to deposit the ceramic ink on a plane with a constant deposition speed of $20 \mathrm{~mm} . \mathrm{s}^{-1}$. The spacing between two rods (from rod center to rod center) was fixed to $300 \mu \mathrm{m}$. After finishing the deposition of several parallel rods, the nozzle was displaced in the vertical direction and another layer of rods was deposited in a direction perpendicular to the previously deposited rods. The process was continued until all the layers were deposited. The deposition was made in an oil bath to avoid collapse of the layers during the process. After deposition, the samples were air-dried for 3 days. Finally, a two-step thermal treatment took place. The first step consisted of a debinding treatment at $550^{\circ} \mathrm{C}$ during 2 hours to remove the PMMA spheres (artificial defects) and organic binders. The sintering occurred during the second step at $1100^{\circ} \mathrm{C}$ during 4 hours. During sintering, it was expected that the large artificial defects would remain unsintered while the small pores between solid particles would close. The heating rate was $1{ }^{\circ} \mathrm{C} / \mathrm{min}$ until $550^{\circ} \mathrm{C}$ and $2^{\circ} \mathrm{C} / \mathrm{min}$ from 550 to $1100^{\circ} \mathrm{C}$. The cooling rate was $5^{\circ} \mathrm{C} / \mathrm{min}$. The overall approach described in this paper (i.e., ex situ compression test, image processing steps, and FE modeling) was applied to one sample. This is justified by the difficulty to reproduce this timeconsuming approach to a large number of samples. For this reason, our goal was to develop a qualitative approach about the influence of the defects on the macroscopic behavior. The results presented in this paper concern a sample with dimensions of $3.58 \mathrm{~mm}$ (in direction 3 , which was the layer-by-layer direction during fabrication and the loading direction during compression), and $4.62 \mathrm{~mm}$ and $4.58 \mathrm{~mm}$ (length and width, directions 1 and 2, respectively).

\subsection{Structural characterization}

Different characterization methods were used. (1) Geometric relative density was calculated from the weight and the dimensions of the sample, considering a density of $3.16 \mathrm{~g}_{\mathrm{gm}} \mathrm{cm}^{-3}$ and $3.14 \mathrm{~g} . \mathrm{cm}^{-3}$ for the fully dense HA and $\beta$-TCP, respectively. (2) One of the faces another sample was carefully polished to $1 \mu \mathrm{m}$ with diamond paste to observe the solid phase. After polishing, the sample was cleaned by ultrasonic bath to remove the polishing debris in the pores. After polishing, the sample was etched by a thermal treatment at $1000^{\circ} \mathrm{C}$ over 1 hour. Then the polished and etched face was observed with scanning electron microscope (SEM), (ZEISS, SUPRA55 VP, Germany) at a voltage of $1 \mathrm{kV}$ without metallization. (3) The phase composition was identified by X-ray diffraction (XRD, Siemens D-500, Munich, Germany) using $\mathrm{Cu} \mathrm{K} \alpha$ radiation $(\lambda=0.15406 \mathrm{~nm})$. The acquisitions were carried out at a scanning rate of $1.8^{\circ} \mathrm{min}$ in the $2 \theta$ range of $20-80^{\circ}$. The HAp, $\beta$-TCP and $\alpha$-TCP were searched by comparison with the JCPDS cards 09-0432, 09-0169 and 09-348 respectively. The weight ratio of the phases was also determined. (4) Mercury intrusion porosimetry (Auto Pore IV, Micromeritics, USA) was used to determine the interconnection pore size distribution by intrusion of liquid mercury into the pores with a maximal pressure of $400 \mathrm{MPa}$. 


\subsection{X-ray tomography}

A laboratory X-ray tomograph (v/Tome/X, Phoenix, Germany) described in detail by Buffière et al. [29] was used to scan the whole sample in its initial state at a "low" resolution of $15 \mu \mathrm{m}$. The tomograph was operated at a voltage of $80 \mathrm{kV}$ and an intensity of $280 \mu \mathrm{A}$ with no filtering on incident X-rays. The 3D final images were then obtained by a standard filtered back projection algorithm implemented in the software coupled to the tomography [30]. To observe the finer details of the microstructure in this initial state, local tomography was used [31]. For this, the sample was placed near the X-ray source; the detector's field of view was then smaller than the size of the sample. This resulted in only a part of the sample (the cylinder of reconstruction) being irradiated by X-rays under all the viewing angles. Some authors have proved that reconstruction can be performed in this local mode $[32,33]$. It is particularly well adapted to porous samples due to their low density [31]. The reconstructed tomogram has a lower signal to noise ratio than in conventional tomography, but a high resolution (voxel size of $3 \mu \mathrm{m}$ ) reconstruction of the irradiated part of the sample can be obtained. To scan another part of the sample, it was necessary only to physically displace the specimen above the rotating stage. Finally, we gathered eight high-resolution images, each representing a part of the sample, to have a representation of the whole sample.

To complete the characterization by X-ray tomography in the initial state, small pieces of rods were additionally scanned with a second higher resolution tomograph described by Etiemble et al. [34] (EasyTom Nano, Rx Solutions, France) with a voxel size of $0.7 \mu \mathrm{m}$. The rods were scanned with a tension of $60 \mathrm{kV}$ and an intensity of $150 \mu \mathrm{A}$ without using local tomography.

An ex situ uniaxial compression test was finally performed to follow the crack initiation and propagation in the sample at low resolution (voxel size of $15 \mu \mathrm{m}$ ). The sample was incrementally loaded outside of the tomograph thanks to a BOSE Electroforce 3200 compression machine (Prairie Valley, USA) equipped with a $200 \mathrm{~N}$ load cell and a capacitive displacement sensor, and scanned in the tomograph after the application of different levels of strain. To test the samples at higher loads (above $200 \mathrm{~N}$ ), an Instron 8502 (High Wycombe, $U K)$ universal hydraulic machine equipped with a $5000 \mathrm{~N}$ load cell and a linear variable differential transformer (LVDT) displacement sensor was used. The test was displacement controlled with a speed of $0.03 \mathrm{~mm} \cdot \mathrm{min}^{-1}$ and was interrupted several times to scan the sample. To avoid contact damage, the two faces of the sample in contact with the loading platens were embedded with paraffin wax for the two testing conditions. Additionally, during the first loading, the sample was unloaded and reloaded six times to calculate the Young's modulus from the unloading slopes.

\subsection{Image processing procedure}

Image processing of the 3D reconstructed tomograms was performed using Image J software [35]. The 8 high-resolution images were first processed to improve the image quality through adjustment of contrast and brightness and the application of a median filter over neighbors of one voxel (Fig. 1a). This figure shows that the artificial defects are indeed present in the sintered rods. Then the images were thresholded to separate the macropores, the ceramic phase, and the artificial defects. Each of these phases had a different grey level (Fig. 1b): 0 for the macro-pores, 128 for the artificial defects, and 255 for the ceramic phase. At this stage, it could have been possible to stitch the thresholded images together to obtain a high-resolution image of the whole sample. However, the result would have been a large image which could not be easily used for finite element modelling. It appears as more relevant to generate an image of the initial sample at a low resolution (i.e., the one used for the ex situ compression test: $15 \mu \mathrm{m}$ ) and containing the information brought by the high-resolution images (i.e., the 
small defects in the solid struts). For this purpose, these high-resolution thresholded images were scaled to change their voxel size from 3 to $15 \mu \mathrm{m}$ (Fig. 1c). The scaling operation preserved the segmentation made at high resolution but blurred the image (as shown in Fig. 1c). To avoid this blurring effect, a second thresholding was performed on the scaled images, using a conservative value of the grey level to make sure that no artificial defect was lost during this step (Fig. 1d). The smallest artificial defects have a typical diameter of 3 voxels at the low-resolution scale. Therefore, they could possibly be lost without this precaution. It must be stated, however, that this procedure clearly results in a non-physical slight increase in the size and number of the artificial defects. Finally, the 8 images were stitched two by two until the image of the whole sample was created (not shown in Fig. 1). The final image of the whole sample contained the information of the presence of the artificial defects in different locations inside the sample, rather than actually describing their morphology in detail. This image was used as an input for the FE model (see section 2.7).

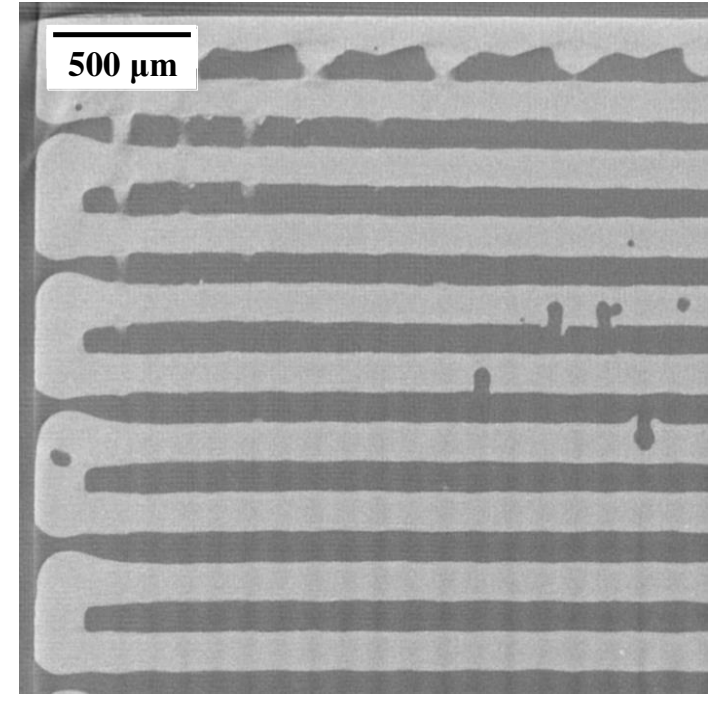

(a)

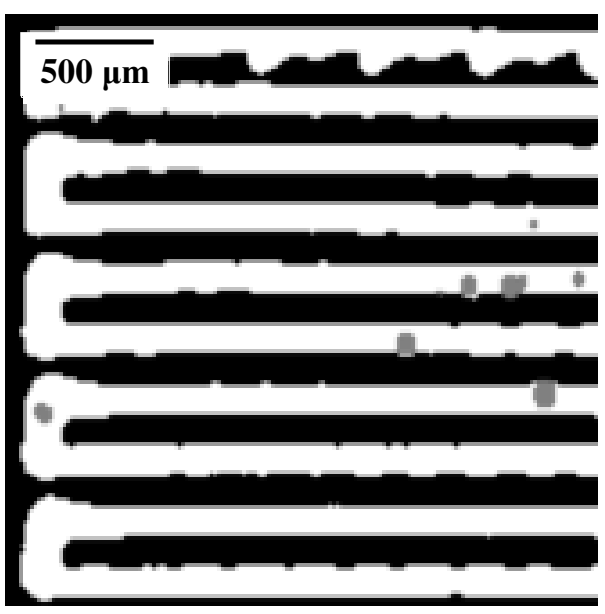

(c)
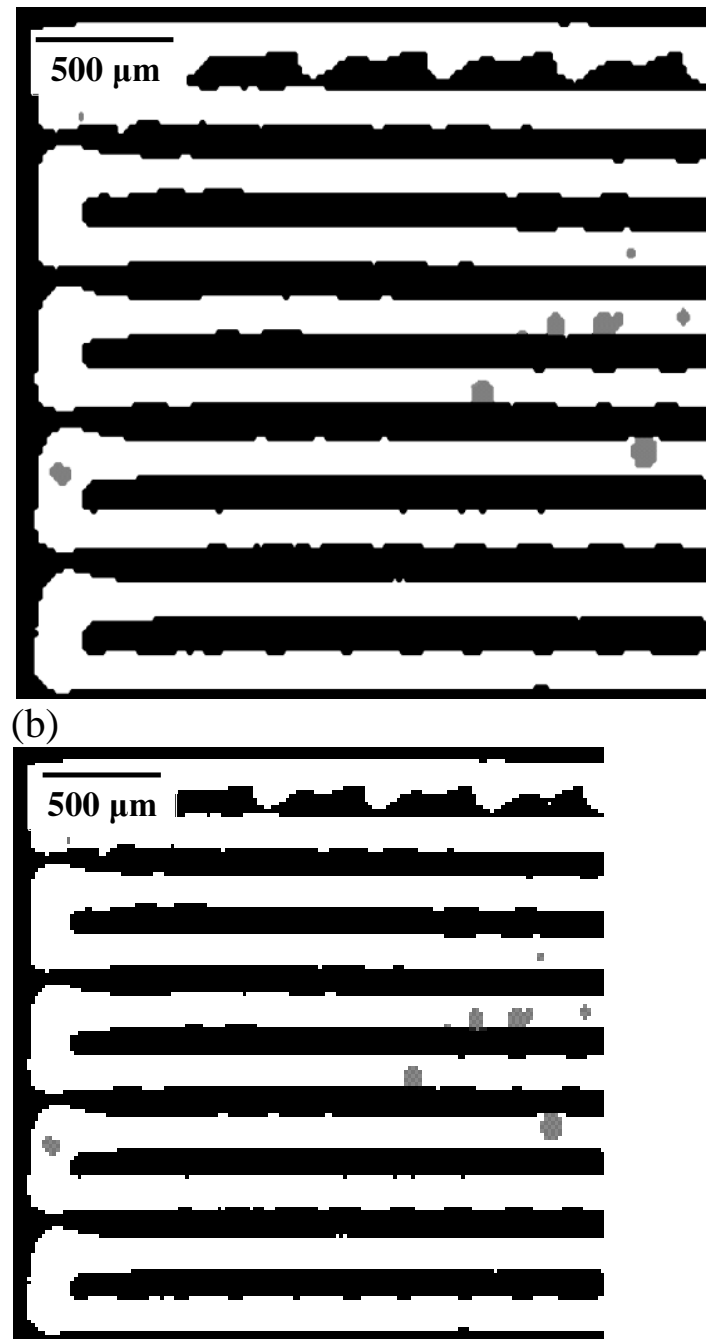

(d)

Fig. 1: (a) Local tomography image slice of part of the sample (voxel size: $3 \mu \mathrm{m}$ ), (b) the same slice after the image processing steps separating the three phases (voxel size: $3 \mu \mathrm{m}),(c)$ the slice after scaling (voxel size: $15 \mu \mathrm{m}$ ), and $(d)$ the scaled slice after the second thresholding (voxel size: $15 \mu \mathrm{m}$ ) 


\subsection{Quantitative analysis of the image}

The high-resolution thresholded images (i.e., those with a voxel size of $3 \mu \mathrm{m}$ ) were used to perform different morphological characterizations, whose measurement principles are explained in detail by Maire et al. [36]. It was performed by applying plugins (i.e., Java programs implemented in ImageJ) to the images. A first plugin aimed at obtaining the relative density of the sample by counting the number of voxels belonging to the solid phase (the white voxels) and dividing it by the total number of voxels. Plots of the relative density in each slice as a function of the location of these slices were also created. A second plugin measured the characteristic size of each phase (rod size and pore size). This was made by applying a series of $3 \mathrm{D}$ erosion and dilation operation with an increasing size to the phase of interest. This measurement can be compared to sieving of a powder [36]. The results were presented as the pores' or rods' sizes distributions in the sample.

\subsection{Determination of the Young's modulus by nanoindentation}

Nanoindentation was performed by an instrumented nanoindentation system (Agilent G200, Agilent Technologies, USA). A Berkovich tip indented polished rods with a speed of $10 \mathrm{~nm} . \mathrm{s}^{-1}$, a dwell time of $10 \mathrm{~s}$, and a maximum load of $100 \mathrm{mN}$. An indentation depth of $2 \mu \mathrm{m}$ was chosen to have an indent size sufficiently large to be representative of the entire rod's elastic properties (i.e., the ceramic phase and the potential residual micropores). A series of 10 indents was made with one indent per rod. The Young's modulus was calculated from the force/displacement curve using the Oliver-Pharr method [37]. A value of $28 \pm 2 \mathrm{GPa}$ was found and used in the FE model (see section 2.7). This value is in agreement with values of Young's modulus obtained by nanoindentation for porous HA and $\beta$-TCP samples with the same volume fraction of micropores considering a rule of mixtures for BCP components [38, 39].

\subsection{FE model}

The image of the initial sample previously fabricated (see section 2.4) was used as an input to build the FE model. The rods (i.e., the ceramic and the artificial defects) were meshed with 1124000 quadratic tetrahedra having an average edge size of $69 \mu \mathrm{m}$ using Avizo 8 software [40]. To differentiate the mesh elements corresponding to the ceramic phase from those corresponding to the artificial defects, a special Java program was developed to create an Abaqus input file where the elements were classified according to their corresponding phase. This program associated the grey levels of the initial image (i.e., 128 for the artificial defects and 255 for the ceramic phase) to each element of the mesh. Two element sets were considered in the simulation: a first one for the elements corresponding to the ceramic and a second one for the elements corresponding to the artificial defects. The macropores between rods were not meshed. A relatively coarse mesh was chosen to ensure a reasonable calculation time, with an average size of $69 \mu \mathrm{m}$, larger than the mean defect size comprised between 35 and $84 \mu \mathrm{m}$ after sintering. An elastic behavior was assumed for the two phases, as this calculation aimed at evaluating the local stresses in the sample. Calculations including a failure criterion were beyond the scope of this paper. The average Young's modulus of the rods was determined by nanoindentation, as previously explained. For the elements corresponding to artificial defects, an empirical Young's modulus of $1 \mathrm{MPa}$ was considered. The mesh was coarse because the elements' average size of $69 \mu \mathrm{m}$ was higher than the defects' size. Thus the elements associated to artificial defects correspond to zones containing mainly artificial defects but also some ceramic phase. A Poisson's ratio of 0.28 was considered 
for the two set of elements [41]. Different negative displacements equivalent to the strains reached during the different loadings in the ex situ test were applied to the nodes of one side of the sample whereas the nodes on the other side were displacement constrained. A reference calculation where all the elements were assigned the behavior of the ceramic phase (i.e., as if the rods did not contain any artificial defect) was also performed. Comparison between the results given by the two calculations could bring information about the influence of the artificial defects on the macroscopic behavior.

\section{Results}

\subsection{Architecture of the sample}

Fig. 2 shows a 3D reconstruction and a SEM image of a part of the sample showing its architecture. The alternation of orthogonal rods from one layer to an adjacent one is clearly visible (see Fig. 2a).

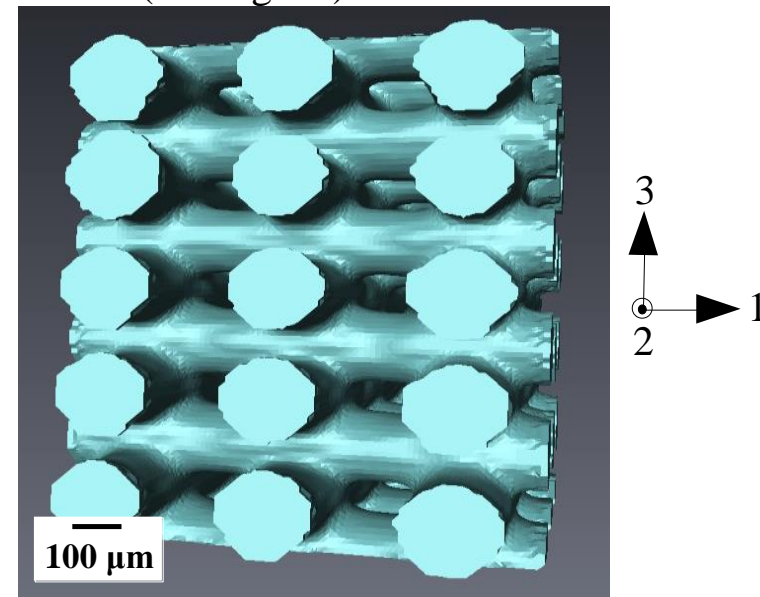

(a)

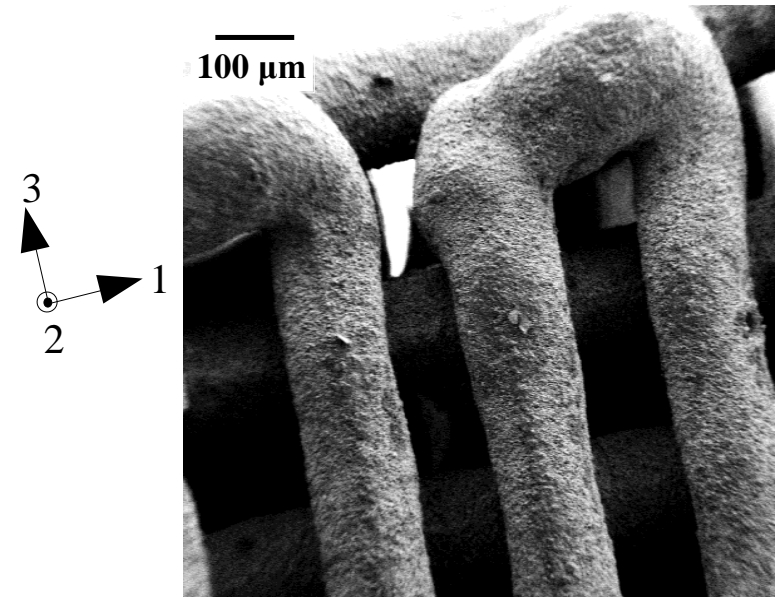

(b)

Fig. 2: (a) 3D reconstruction of a part of the sample from X-ray tomography and (b) a SEM image showing the side of the sample in directions 1 and 2

Fig. 3 gives the relative density distribution measured with the high-resolution images along the sections perpendicular to the three main directions of the sample shown in Fig. 2. Due to the spatial resolution of the technique, micropores resulting from incomplete sintering are not detected and this measure assumes fully dense rods. The relative density calculated from ImageJ is $0.60 \pm 0.01$, meaning a volume fraction of macropores in the whole sample of 0.40 \pm 0.01 . The evolution of relative densities in the cross sections in directions 1 and 2 between a highest value of 0.85 and a lowest of 0.30 is explained by the alternating orthogonal rods. The cross sections with the maximum relative density along direction 1 correspond to sections crossing the rods orientated in direction 2 and the less dense ones to sections crossing the sample between these rods (Fig. 3). Along directions 1 and 2, a higher density is calculated in the first and last cross sections corresponding to the sides of the samples. The higher density is due to the deposition done at the end of the rods. To go from one rod to another, the nozzle does not stop the deposition as shown in Fig. $2 b$ in the plane perpendicular to the deposition. Along direction 3 , the variations of the relative density are less logically important.

Fig. 4a shows the rod size distribution measured by ImageJ with the $3 \mathrm{D}$ granulometry plugin. The rod diameter lies between 119 and $161 \mu \mathrm{m}$ with a peak for a diameter of $147 \mu \mathrm{m}$ and a smaller peak for $126 \mu \mathrm{m}$. The pore size distribution measured by 3D image analysis (Fig. 4b) is characterized by a main peak between 84 and $133 \mu \mathrm{m}$ with a maximum frequency at 120 $\mu \mathrm{m}$. This peak is related to the macroporosity between the rods. The pore size distribution also 
exhibits values between 35 and $84 \mu \mathrm{m}$, corresponding to the artificial defects added by PMMA beads in the rods.
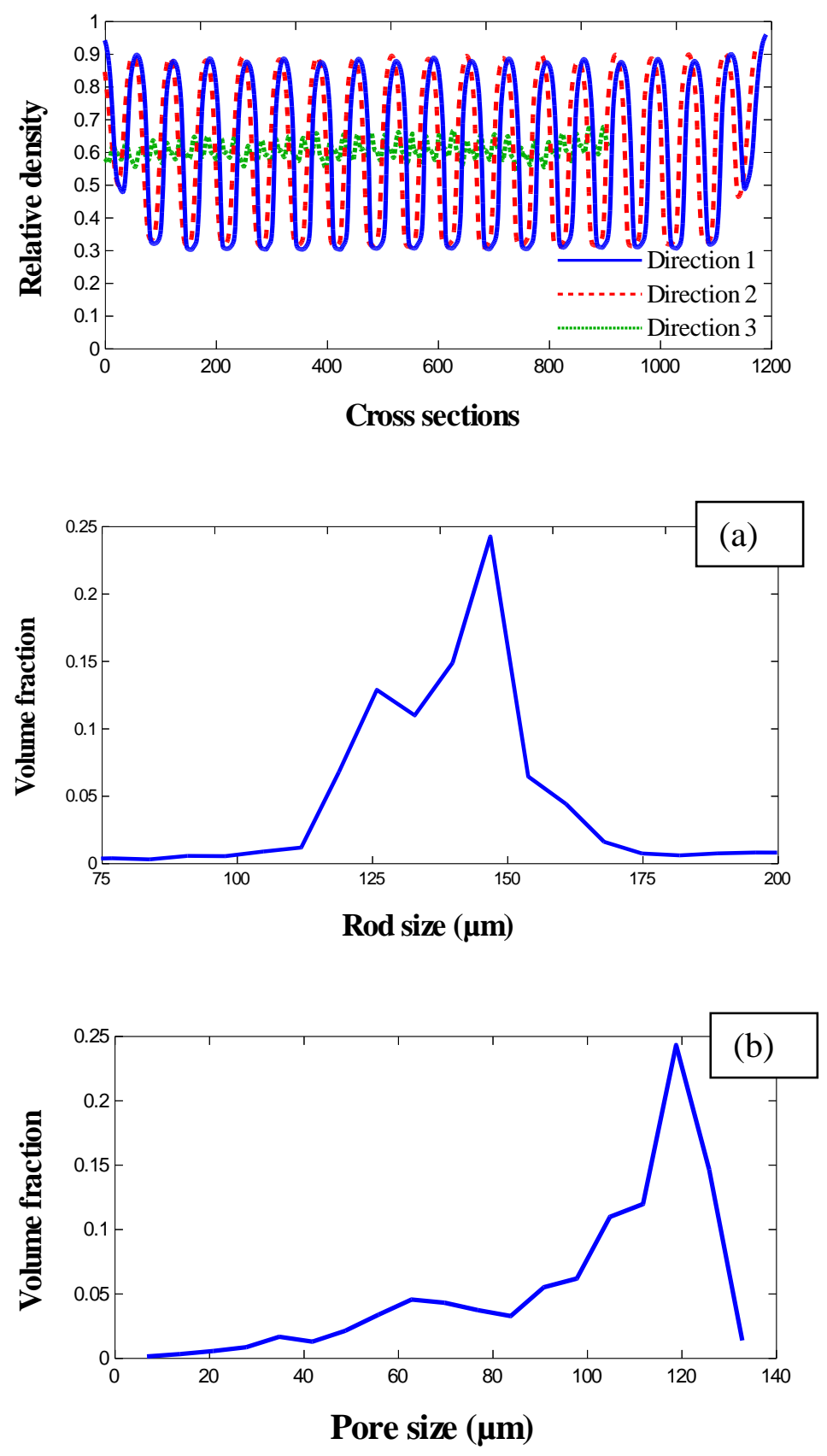

Fig. 3: Relative density distributions along the three main directions calculated by $3 D$ image analysis

Fig. 4: (a) Rod size distribution of the sample obtained by $3 D$ granulometry on a tomographic image and (b) pore size distribution

\subsection{Characterization of the microstructure in the solid rods}

Local tomography (Fig. 5a) gives details on the microstructure of the rods: intentionally added artificial defects (some are highlighted in a red frame) and imperfect boundaries (indicated by an arrow) between two orthogonal layers. As seen in Fig. 5b, the small artificial defects are randomly located in the rods. Due to this random location, they are connected or not to the macropores located between the rods. Some of them have a non-spherical shape (Fig. 5a): these pores with a more elongated shape are probably formed by the burning out of two adjacent PMMA beads. 


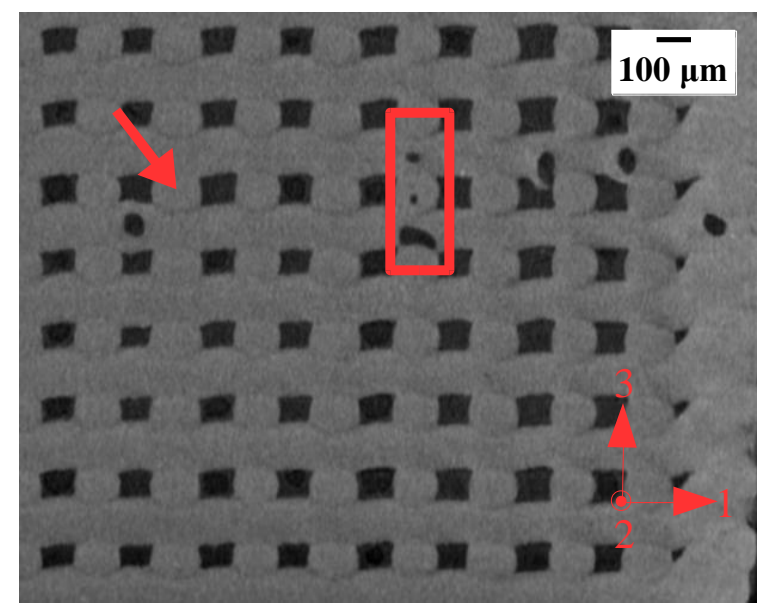

(a)

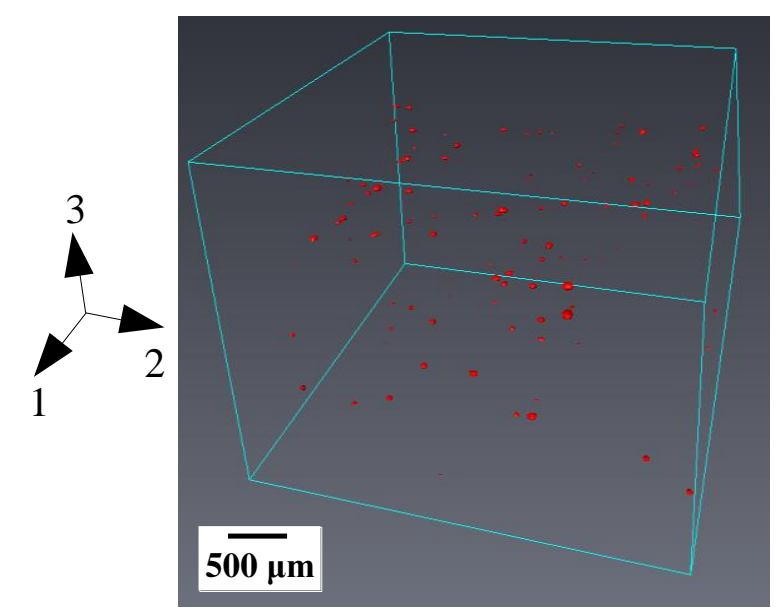

(b)

Fig. 5: (a) Slice of a high-resolution image (voxel size of $3 \mu \mathrm{m}$ ) from local tomography showing artificial defects and incomplete bonding between the different layers (arrows), (b) $3 D$ visualization of the artificial defects from local tomography images

To investigate in more detail the microstructure of the rods, a polished cross section was prepared and observed with SEM. Residual micropores due to incomplete sintering are revealed in the rod (Fig. 6a). This residual porosity is also noticed with specific very highresolution tomography by a difference of grey level values in the rods (Fig. 6b). This tomographic image has a voxel size of $0.7 \mu \mathrm{m}$ and was acquired using a small piece of sample (with dimensions of approximately $1 \times 1 \times 0.7 \mathrm{~mm}^{3}$ ). Moreover, the incomplete sintering at the junction between the two orthogonal rods (already seen in local tomography images in Fig. 5a) is visible in this image.

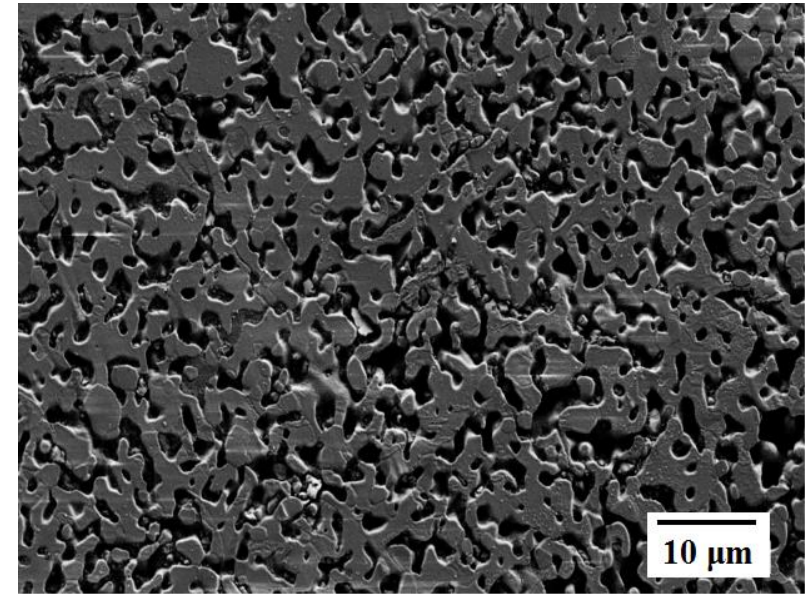

(a)

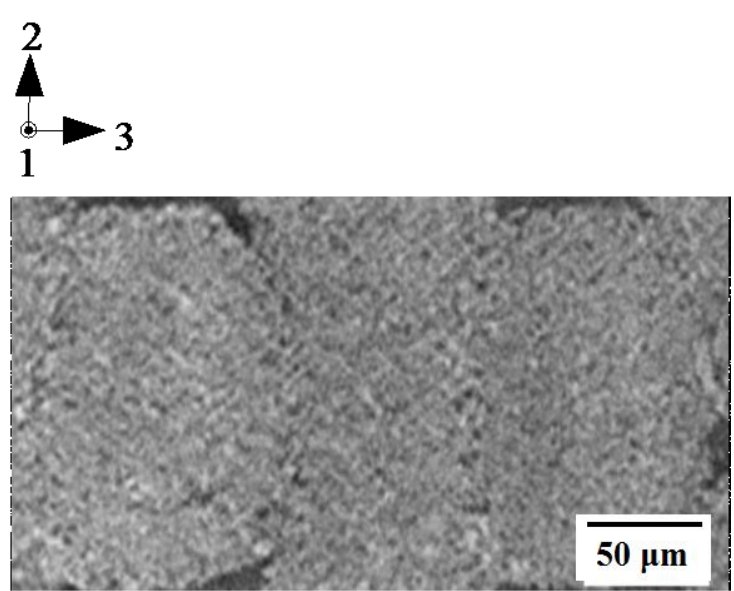

(b)

Fig. 6: (a) SEM image of a cross section of a rod (magnification $x$ 1000) and (b) an X-ray tomography high resolution image (voxel size of $0.7 \mu \mathrm{m}$ ) of several rods

The XRD pattern of the scaffold is shown in Fig. 7. Only HA and $\alpha$-TCP phases are detected and no trace of $\beta$-TCP is found. HA/ $\beta$-TCP weight ratio of $19 / 81$ is obtained. This value is close to the targeted one (20/80). 


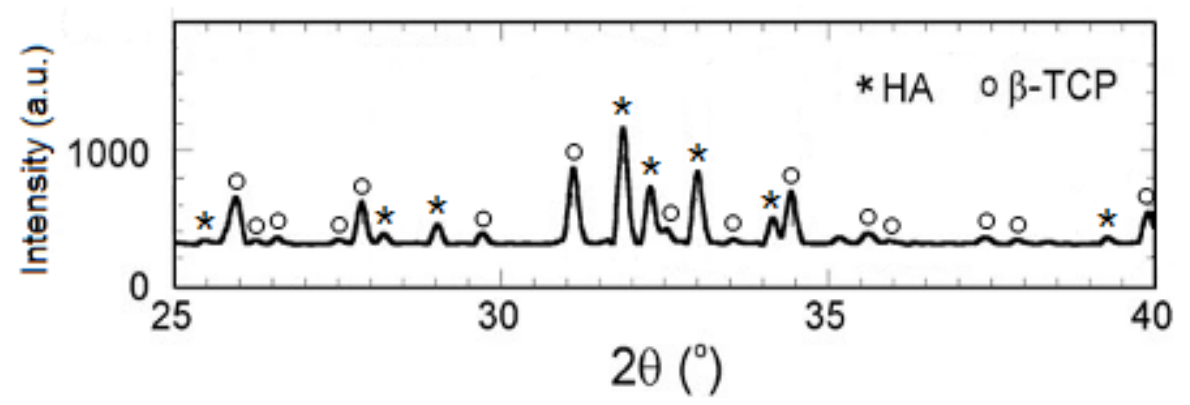

Fig. 7: XRD pattern of the sintered scaffold. HA (*) and $\beta$-TCP ( $\bigcirc)$ are identified with comparison with JCPDS cards 09-0432 and 09-0169 respectively.

The size of the residual pores left by incomplete sintering measured through SEM images is $2.6 \pm 1.1 \mu \mathrm{m}$. In addition, the interconnection pore size distribution of the robocast HA/ $\beta$-TCP sample was measured by mercury intrusion porosimetry (Fig. 8). The peak between 47 and $114 \mu \mathrm{m}$ with a maximum value of $91 \mu \mathrm{m}$ corresponds to the interconnections through the macropores and the open artificial defects. The second peak between 0.3 and $2.4 \mu \mathrm{m}$ with a maximum value of $1.3 \mu \mathrm{m}$ is linked to the intrusion of mercury into the residual micropores left by incomplete sintering.

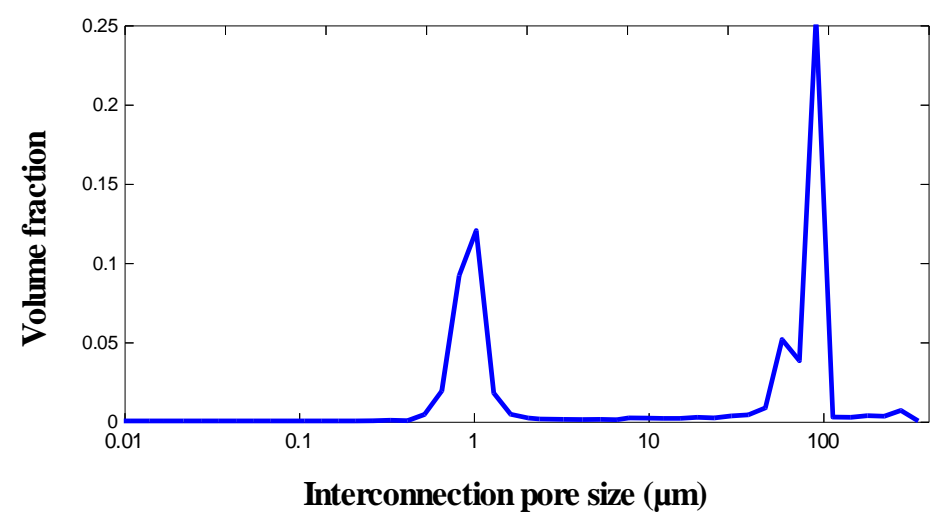

Fig. 8: Pore size distribution measured by mercury porosimetry

Mercury porosimetry reveals a total volume fraction in the sample of micropores with a size lower than $15 \mu \mathrm{m}$ of $0.26 \pm 0.02$. This value is coherent with the difference between the volume fraction of pores obtained by geometric measurement (total porous volume, $0.64 \pm$ 0.02 ) and by image analysis of the tomographic volume (macroporous volume, $0.4 \pm 0.01$ ). Consequently, the respective volume fractions of each type of pores in the whole sample are 0.4 for macropores, 0.26 for residual micropores and 0.012 for artificial defects. These values give a total volume fraction of pores in the whole sample of 0.67 which is coherent with the geometric value of 0.64 . The difference can be explained by some errors in the measurement (resolution of the tomographic volume used, presence of some micropores which were not impregnated by mercury during porosimetry measurement). In the rods, the volume fraction of pores is 0.02 for the artificial defects and 0.43 for the micropores.

\subsection{Ex situ compression tests}

Fig. 9a presents the stress/strain curves obtained for the sample during the ex situ test. The black curve represents the entire stress/strain curve, until the rupture of the sample. The other curves correspond to four loadings interrupted to scan the sample at different strains. An inset 
on the beginning of the stress/strain curve is also shown in Fig. 9b. The shape of the curve is discussed in the next section. The mechanical behavior is characterized by a linear elastic part followed by a plateau before brittle failure. The compression strength (i.e., the maximum stress reached during the test) is $14.2 \mathrm{MPa}$. Table 1 presents the values of compression strength for the sample and values from literature which will be commented in the Discussion section.
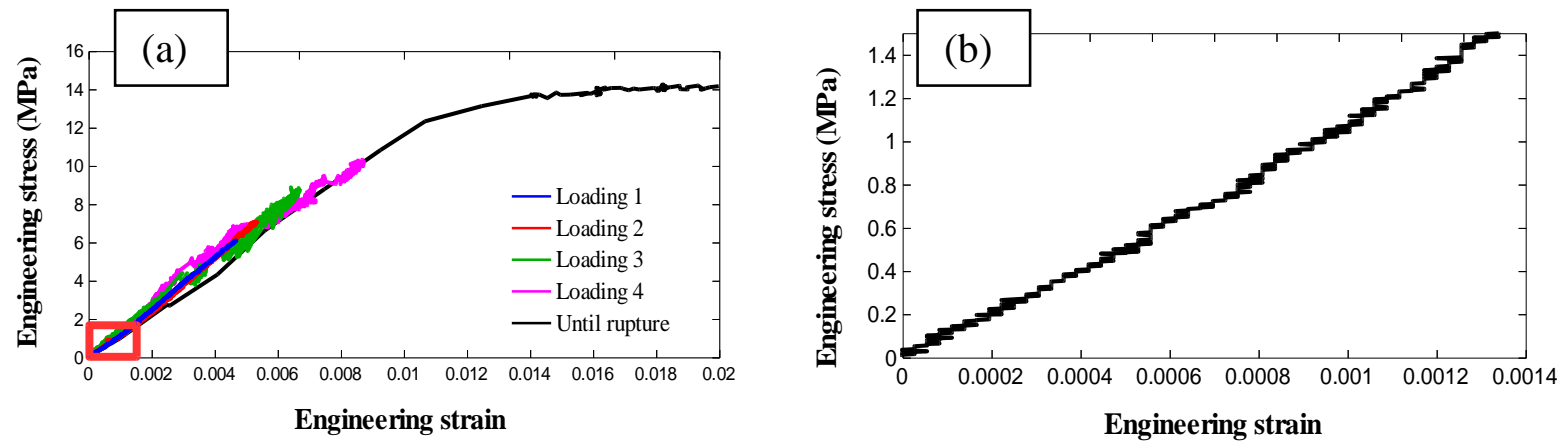

Fig. 9: (a) Compression stress/strain curves corresponding to the successive loadings and to the test until rupture (black curve) and (b) a magnified view of the final stress/strain curve's beginning showing the increase of stiffness in the linear part

Table 1: Values of effective Young's modulus calculated from the loading/unloading curves

\section{Calculation}

Average on the four unloading curves

First unloading curve (Fig. 8)

Fourth unloading curve (Fig. 8)
Effective Young's modulus (GPa)

$2.31 \pm 0.33$

Average on the four loading curves

$1.47 \pm 0.19$

Fig. 9 presents a loading and two unloading curves for the sample at low strains used to calculate the Young's modulus. The stiffness is higher during the unloading cycle compared with the loading cycle (Fig. 9), and reaches the highest value at the onset of unloading. The stiffness during unloading increases with the cycle number. Loading/unloading hysteresis is also visible in the curve as well as an irreversible residual strain at the end of the unloading steps. The effective Young's modulus was calculated from the loading and unloading parts of the loading/unloading cycles (Fig. 10). The different values obtained are summarized in Table 1. A higher value of Young's modulus $(2.3 \mathrm{GPa})$ is obtained compared with the value obtained with the loading curve (1.5 GPa). The Young's modulus increases as the loading/unloading cycle number increases. The reason for these differences is discussed in the next section. In the case of the Young's modulus, a comparison with the literature is very difficult because this parameter is highly dependent on the relative density, the fabrication process, and the volume fraction of the two phases (HA and $\beta$-TCP). In a previous study, we obtained a Young's modulus of $1.38 \mathrm{GPa}$ (calculated with unloading curves) for a randomly porous $\beta$-TCP with a relative density of 0.29 [26]. 


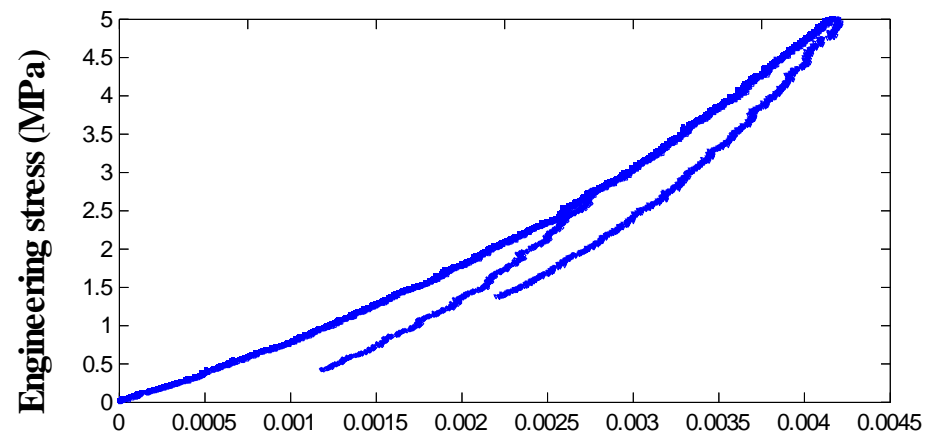

Engineering strain
Fig. 10: Loading and unloading cycles undergone by the sample. The loading curve corresponds to the first loading curve of the Fig. $8 a$.

Fig. 11 and 12 show the evolution of the crack in two vertical slices corresponding to two different locations in the sample during the ex situ compression test. The location of these two slices in the sample is indicated in Fig. 11a and 12a. The slice shown in Fig. 11 is located near a sample's free surface. The crack initiates from this side as shown with the red arrow and in the insight in Fig. 11c. As the test continues, this crack further propagates along direction 3. The second slice (Fig. 12) located inside the sample shows the crack propagation in direction 2. The crack reaches this section of the sample after the third loading (see the red arrows in Fig. 12d). At the end of the test, the crack separates the sample into two parts. In addition, the insight in Fig. 11c shows the crack initiates in a rod where an artificial defect is present. A second defect is also present close to the first one in the left. These two close defects can act as stress concentrators and initiate the crack. However, this image does not allow for concluding exactly about the precise location of the crack initiation because the crack could also be initiated from the macropores located below. Section 3.4 details the results of the FE calculations. 


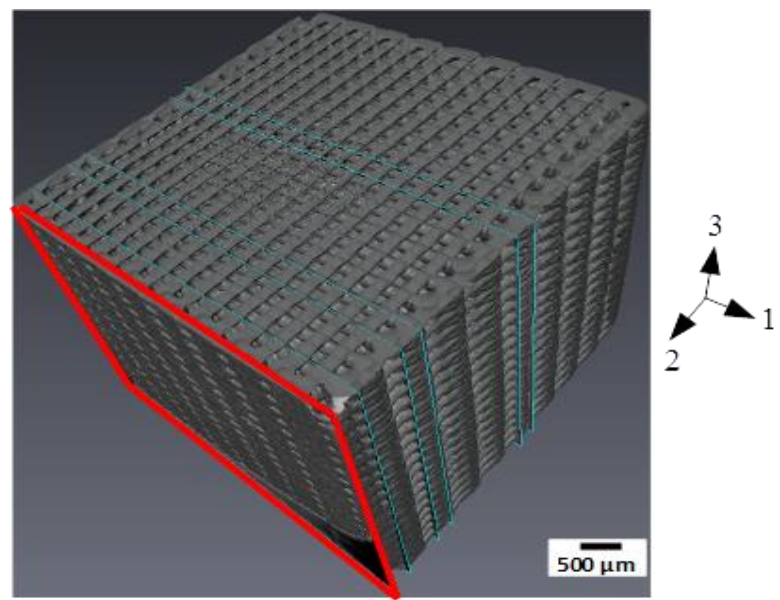

(a)

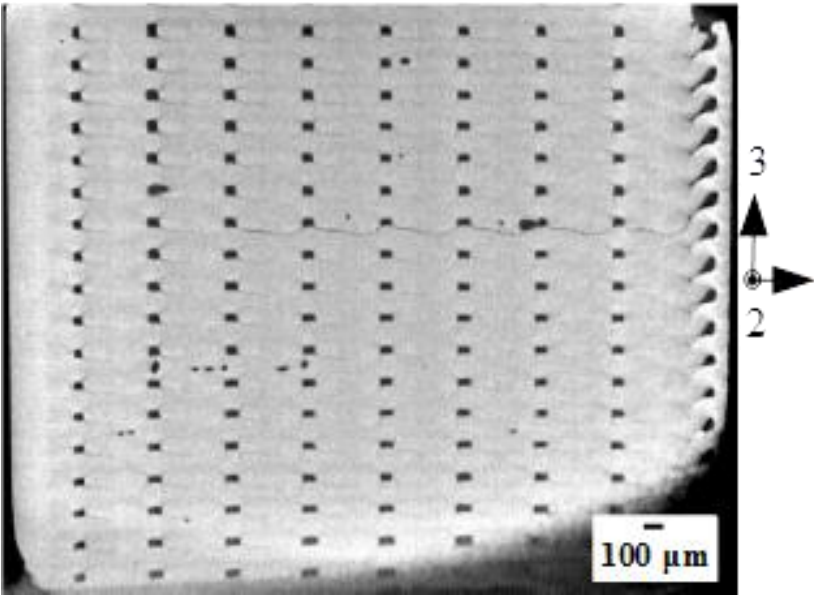

(b)

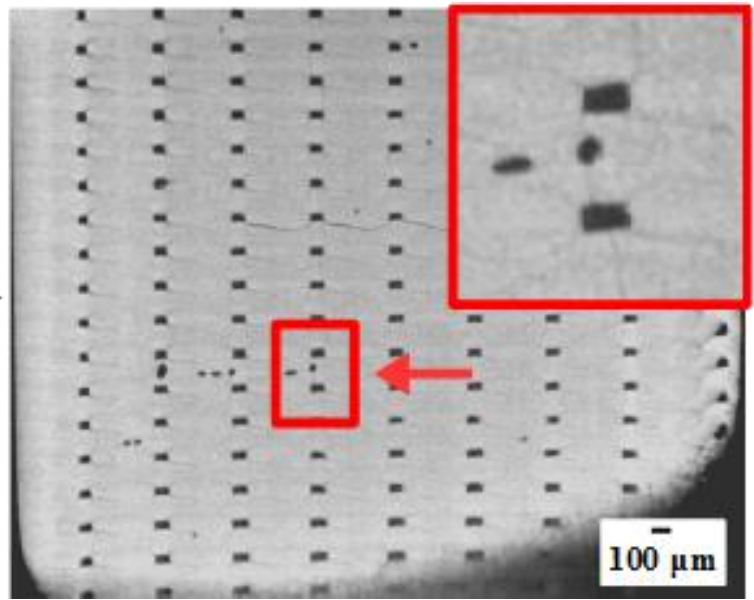

(c)

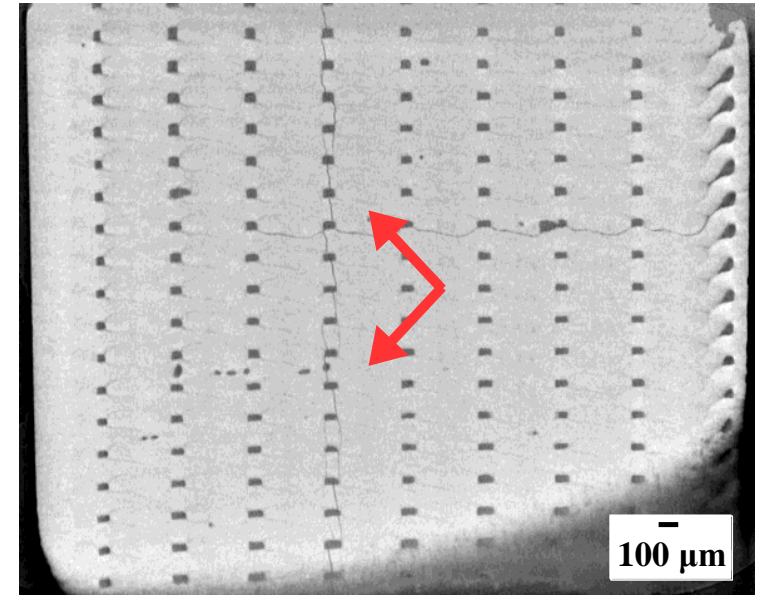

(d)

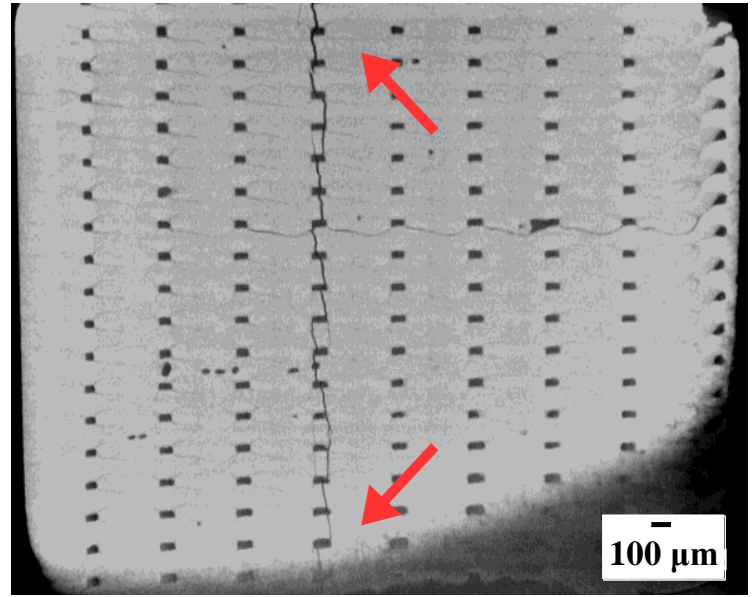

(e)

Fig. 11: (a) 3D reconstruction of the sample showing the location of a vertical slice (red frame) which is presented after at different steps of the ex situ compression test: (b) at the initial state, (c) after the second loading (with a magnified view on the crack initiation), (d) after the third loading, and (e) after the fourth loading (red arrows show the crack initiation and propagation) 


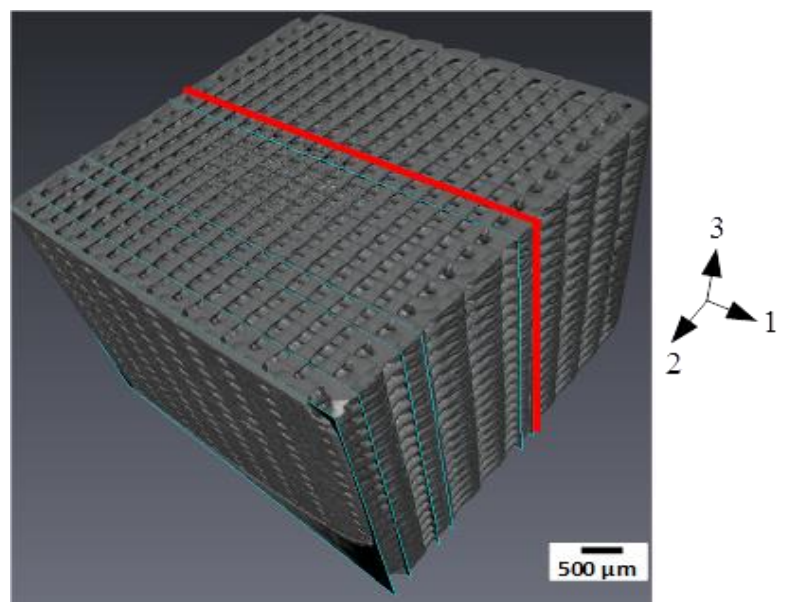

(a)

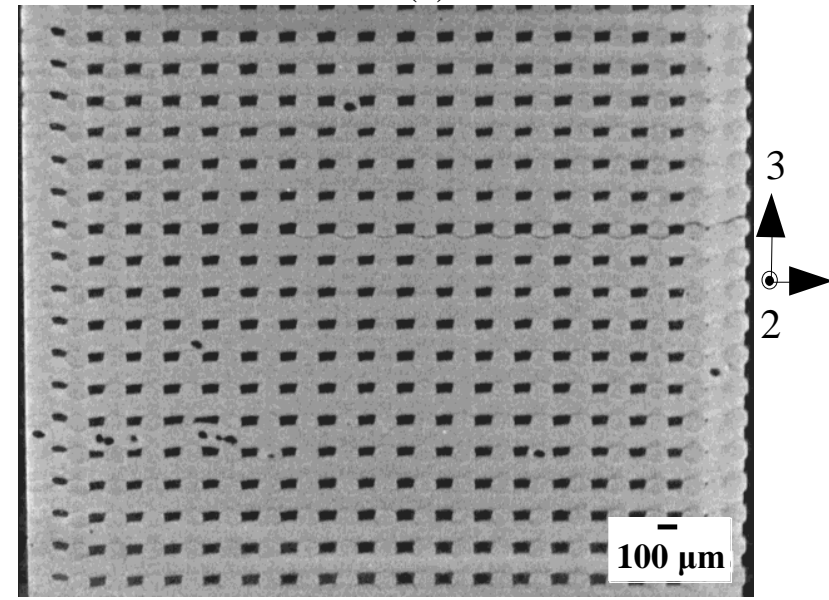

(b)

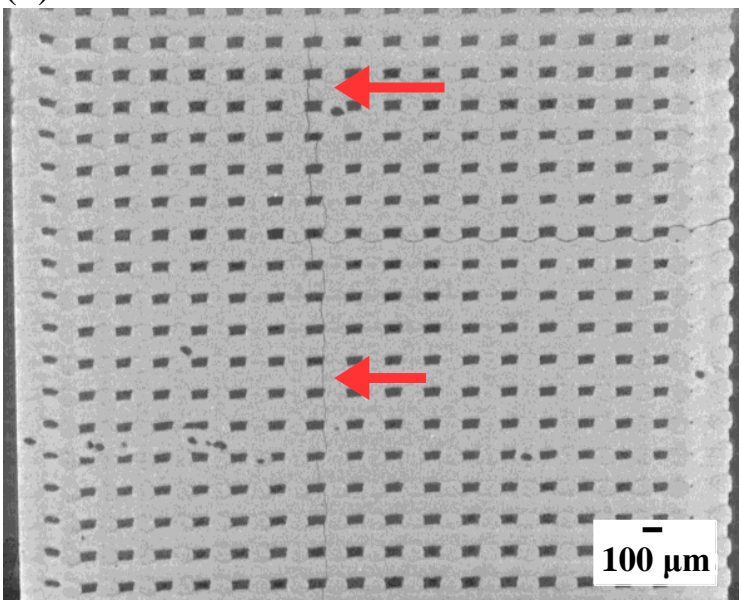

(d)

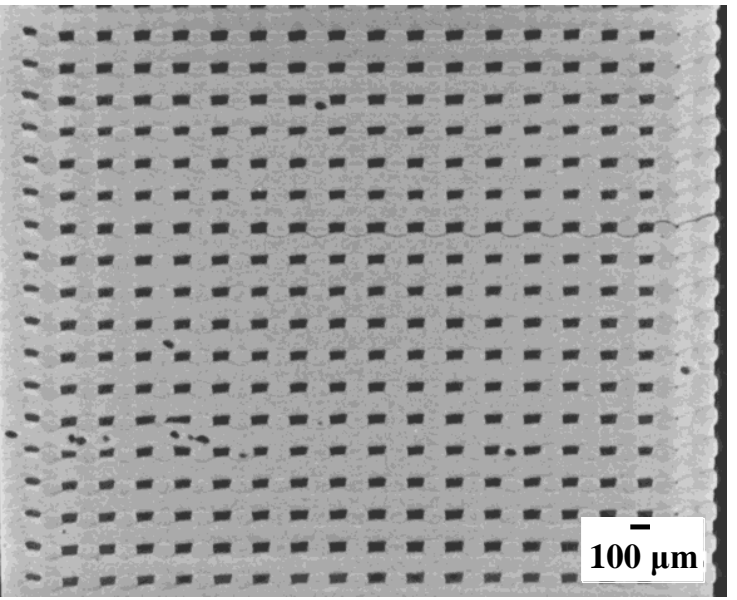

(c)

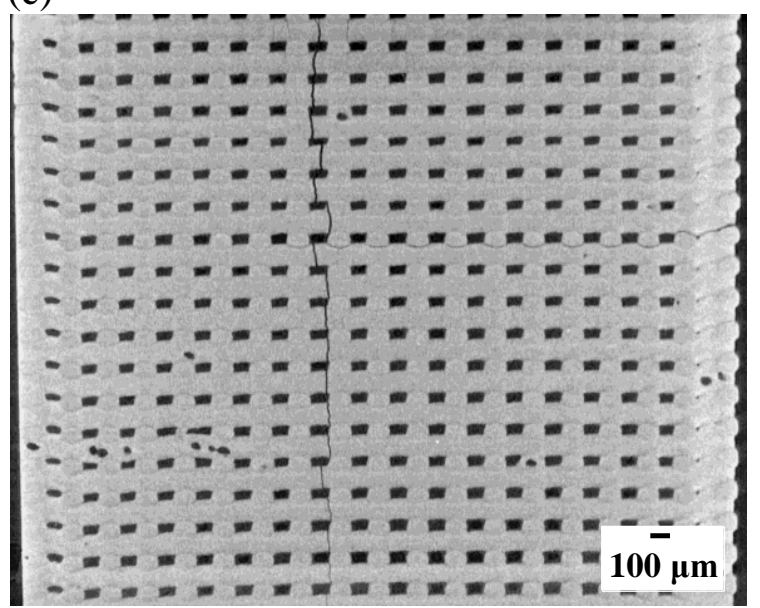

(e)

Fig. 12: (a) 3D reconstruction of the sample showing the location of a second vertical slice (red frame) which is presented after at different steps of the ex situ compression test: $(b)$ at the initial state, (c) after the second loading, (d) after the third loading, and (e) after the fourth loading (red arrows show the crack initiation and propagation)

\subsection{FE modeling}

Fig. 13 presents results of the FE calculations. The calculated local stresses in the slice where the crack initiation is visible (see Fig. 11c) are shown in Fig. 13a (reference calculation without the artificial defects) and 13b (calculation with the artificial defects). Magnified views 
on the crack initiation are presented in Fig. 13c (tomographic slice), 13d (reference calculation without the artificial defects) and $12 \mathrm{e}$ (calculation with the artificial defects). Without the artificial defects (Fig. 13d), high stresses are predicted in the horizontal rods and especially near the joints with the orthogonal rods. This is consistent with the experimental observations, which show the propagation of the crack in the horizontal rods. The stress distribution in the section is logical because it is controlled by the periodic structure. When including the artificial defects, the stress distribution appears to be different (Fig. 13e). Different stress concentrations are observed in the vicinity of the artificial defects. In the zone where the crack initiates, the calculation without the artificial defect does not predict higher stress between the two macropores (see the yellow frame in Fig. 13d). When the artificial defects are taken into account, stress concentrations appear around the defect (see the yellow frame in Fig. 13e). A comparison between Fig. 13d and 13e shows that the stress concentrations are present along the crack path. The second artificial defect present in the left also creates stress concentration in its vicinity (see the purple frames in Fig. 13d, and 13e). Finally, with the artificial defects in the model, an increase of stress is noted in a horizontal rod where no artificial defect is present (compare the bottom part of the images in Fig. 13d and $13 \mathrm{e})$.
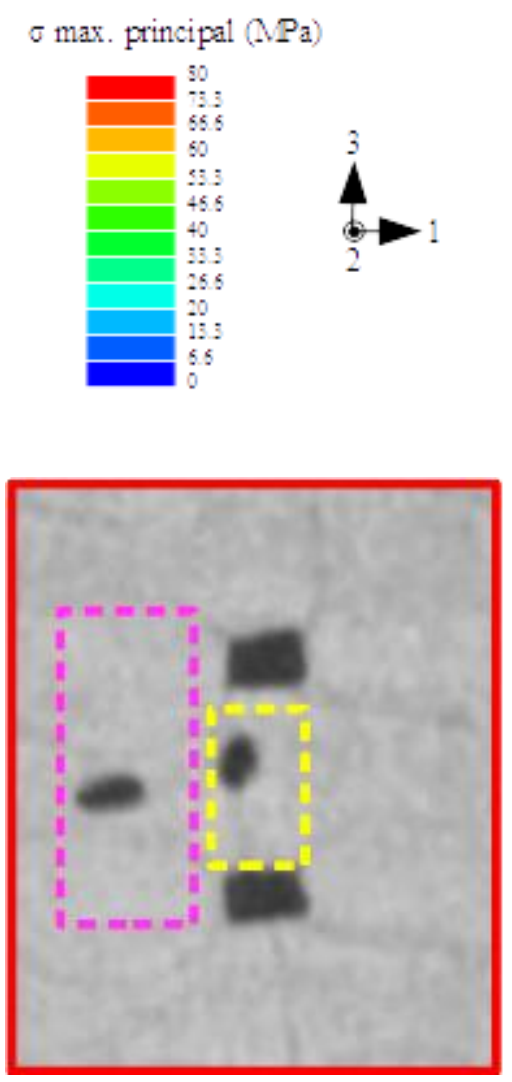

(c)

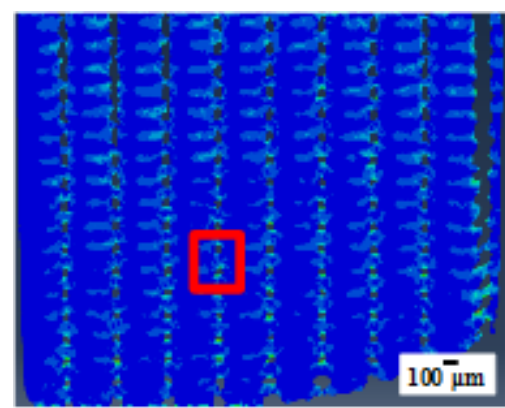

(a)

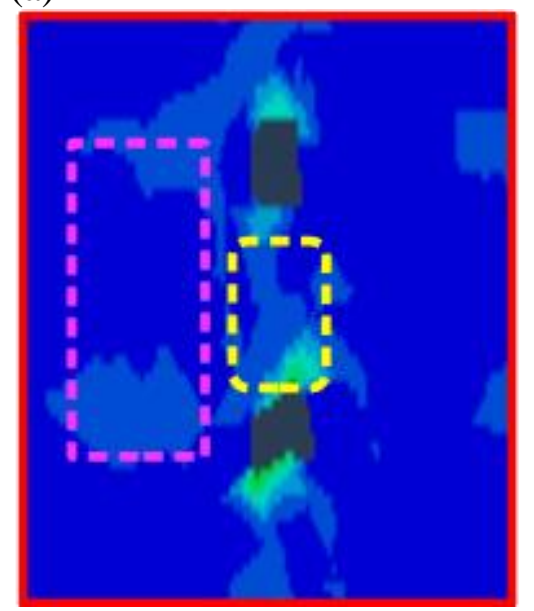

(d)

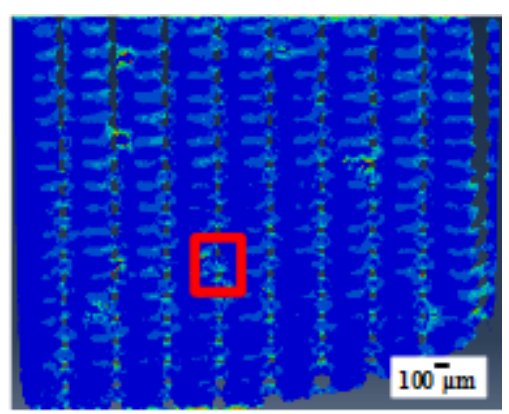

(b)

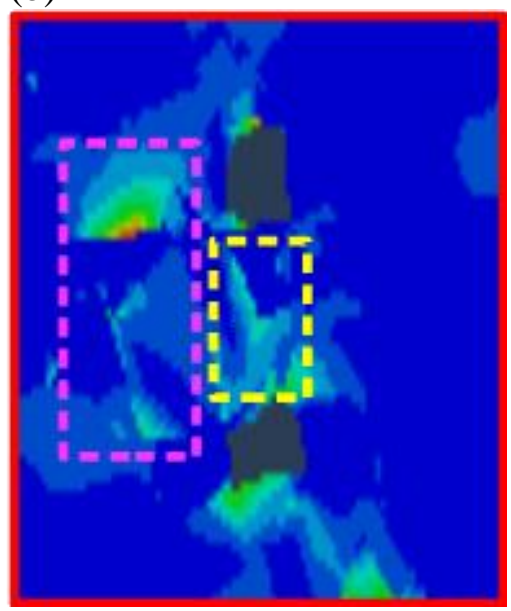

(e)

Fig. 13: Contours of the calculated maximal principal stress for the calculation (a) without and (b) with the artificial defects, (c) magnified view of the slice from tomographic image on the crack initiation, and $(d)$ and (e) magnified views of the contours where the crack initiates. In (d) and (e), a yellow arrow points out the stress field around the artificial defect crossed by the crack, and a yellow frame shows the stress field around the second artificial defect. The yellow arrow and frame are reported in (c) to illustrate the exact location of the defects. 


\section{Discussion}

\section{Characterization of the robocast samples}

The cellular ceramic sample considered here shows a square prism periodic structure. It has a high volume fraction of pores (0.64). However, the macropores, which characterize the macroscopic structure, only represent 0.4 of the whole sample. The difference between these two values represents the fraction of micropores and artificial defects in the solid rods of the sample. The sintered rods are not fully densified, as testified by an internal volume fraction of micropores of 0.43 . This can be related to the relatively low sintering temperature of $1100^{\circ} \mathrm{C}$ leading to a limited densification of the ceramic, as already noted by several authors $[42,43]$. However, this temperature was chosen to avoid the phase transformation from $\beta$ to $\alpha$-TCP which generally occurs around $1150^{\circ} \mathrm{C}[44,45]$. A small amount of $\alpha$-TCP phase has already been detected in similar HA/ $\beta$-TCP scaffolds sintered at $1140^{\circ} \mathrm{C}$ [22]. It is known that $\alpha-\mathrm{TCP}$ can have a detrimental effect on the mechanical properties $[42,44]$. HA/ $\beta$-TCP weight ratio of $84 / 16$ was found in the sintered sample whereas a value of $80 / 20$ was targeted. These close values show that the robocasting and sintering did not affect the sample's chemistry.

During the robocasting process, the syringe diameter was $150 \mu \mathrm{m}$. Considering the solid loading of the ceramic ink of $30 \mathrm{vol} \%$ and the relative density of the sintered rods of $57 \%$, the volume shrinkage is $46 \%$ and the linear shrinkage is $13 \%$. Thus, the expected rod diameter after shrinkage is $130 \mu \mathrm{m}$. This is consistent with the measured rod diameter distribution between 119 and $161 \mu \mathrm{m}$. The highest values probably correspond to rod overlapping between two adjacent rods. It is important to note that we neglect a possible elastic movement of the ink when it is deposited.

A rod spacing (from center to center of the rods) of $300 \mu \mathrm{m}$ was chosen for the ink's deposition. Considering the nozzle diameter of $150 \mu \mathrm{m}$, it means that during the process, the space between two rods was $150 \mu \mathrm{m}$. Since the rods shrink in every dimension during sintering, the macropore size is also expected to decrease in the same proportion: thus the expected macropore size is also $130 \mu \mathrm{m}$ (for $150 \mu \mathrm{m}$ during deposition). The experimental macropore size is between 84 and $133 \mu \mathrm{m}$. This may be explained by an elastic "displacement" of the ink when it gets out of the nozzle and by the rod collapse during drying. This phenomenon is shown in Fig. 6b, with an interpenetration of the rods between adjacent layers and of non-perfect bonding between rods. The use of local tomography allows the observation of these types of defects due to fabrication processes (Fig. 5a and 6b) even if the overall structure seems to be regular (Fig. 2a). Local tomography also shows the artificial defects having a size between 35 and $84 \mu \mathrm{m}$. After shrinkage, the expected artificial defects' size range is $39-87 \mu \mathrm{m}$ due to the PMMA beads' size range $(45-100 \mu \mathrm{m})$. The robocast samples are often observed by microscopy, which does not provide a complete characterization $[17,19]$. This study shows the importance of a 3D characterization of the scaffolds, especially with local tomography.

\section{Mechanical behavior in compression}

The stress/strain curve of the sample in uniaxial compression is characterized by a first elastic domain followed by a stress plateau. Non-linearity is observed in the elastic part of the loading curves with an increase of the axial stiffness (Fig. 9b) as the applied stress increases. This has already been observed during compression tests of porous ceramics [46] or rocks [47]. The increase of stiffness with increasing load has been attributed to a progressive closure of microcracks favorably oriented relative to the loading direction. High-resolution images show the presence of such defects, such as imperfect bonding between the layers (Fig. 5a and $6 b)$. The non-linearity can also be explained by the removal of the samples after each loading cycle for scanning. Crack re-opening possibly occurs during sample handling between scans. 
Additionally, the two faces in contact with the compression platens were embedded with paraffin wax to avoid local brittle fracture near the faces. Therefore, the increase of stiffness can also be due to a first compression of the wax before the "real" compression of the specimen. Then, at the onset of unloading, the stress/strain curve is linear: no mechanism associated with non-linearity is active. The axial stiffness slowly decreases during unloading, possibly due to the opening of the closed cracks and/or sliding of the closed cracks' faces [46, 47]. This axial stiffening of the unloading curve can explain the higher value obtained for the effective Young's modulus calculated during unloading as compared to loading (Table 1). Finally, the increase of the stiffness at the onset of the unloading curves with the loading/unloading cycle number (Fig. 10) can be linked to an increased crack closure at higher applied strains. At high applied strains, the elastic domain is followed by a stress plateau: it usually corresponds to the damageable behavior commonly observed for highly porous ceramics with a stochastic microstructure. In this latter case, it is characterized by the propagation of multiple small cracks in the solid phase of stochastic porous ceramics [48]. In this study, although the robocast sample has a total volume fraction of pores of 0.64 , a behavior characteristic of dense brittle ceramic is observed with the propagation of a main crack parallel to the loading direction. The rupture is not perfectly brittle because the ex situ compression test shows that the crack propagates step by step along the sample. This specific behavior has already been observed by Miranda et al. [24] with robocast HA scaffolds.

Because of the high volume fraction of pores, we could have expected a damageable behavior with the propagation of multiple small cracks. It seems that the observed brittle-like behavior is rather explained by the volume fraction of macropores (0.4) significantly lower than the total porous volume. A transition from a brittle-like to a cellular-like behavior with the increase of volume fraction of pores has been observed by Meille et al. [49] for a macroporous alumina with a stochastic microstructure. In this latter study, the transition between the two behaviors occurred at a volume fraction of pores of around 0.5. It seems therefore than the brittle or damageable character in uniaxial compression is mainly controlled by the macroporous volume fraction. It confirms observations made in our previous study about a macroporous $\beta$-TCP sample [26]. This sample having a volume fraction of macropores of 0.5 exhibited a damageable behavior.

\section{$\underline{\text { Specific use of two-scale X-ray tomography in the study of cellular ceramics }}$}

Local tomography allows to have a new insight on the rods' structure and the sample's mechanical behavior. They allowed observing the artificial defects in the rods which have an influence on the crack initiation. In addition to the artificial defects, other defects (e.g., imperfect bonding between layers) are detected. The presence of defects in structures made by $\mathrm{AM}$ and their influence on the mechanical behavior have already been noticed in metallic samples [50]. This means that crack initiation and propagation could be delayed if the defects due to the fabrication process could be removed. Therefore, further work is needed to improve the robocasting process and obtain defect-free specimens.

The high-resolution images were also processed to be used as an input for FE modeling. In this paper, an original two-scale method was developed to take into account the details of the microstructure revealed by local tomography in a model of the material at a lower resolution. This avoided the use of very large images and long calculation times. Our approach allowed having a lightweight mesh of the macrostructure including information about a finer scale. The calculated local stress distribution is modified by the presence of the artificial defects (see Fig. 13d and e). A high stress concentration is present around the two main defects where the crack initiates during the experimental test (Fig. 13e). However, another stress concentration is visible below a macropore where no artificial defect is present (see the bottom part in Fig. 
13e) and no crack initiation occurs at this location. This stress concentration may be related to the imperfect bonding between adjacent layers which can be distinguished in the tomographic slice (see the bottom part of Fig. 13c). This means that the link between the stress distributions predicted by FE models and the crack path is not obvious. To perform calculations within a reasonable time, we meshed the 3D images with tetrahedra with an average edge size of $69 \mu \mathrm{m}$. This resulted in a relatively coarse mesh with some approximations in the geometrical description of the sample, especially around the artificial defects. A refinement of the mesh or the use of higher resolution images could bring more accurate results. The simple elastic simulation presented here could also be completed by calculations with a more realistic behavior (for instance, damageable behavior) for the ceramic material.

\section{Conclusions}

This paper focuses on the analysis of the fracture behavior in compression of a robocast biphasic calcium phosphate scaffold. This sample consist of different layers of parallel rods, the rods of one layer being perpendicular to the rods of the adjacent layer. They contain three types of pores: a macroporosity of hundreds of $\mu \mathrm{m}$ between the layers defining the architecture of the specimens, artificial defects with a size $30-80 \mu \mathrm{m}$ intentionally added in the rods, and residual pores due to incomplete sintering with a size of a few microns.

The ex situ compression test reveals a brittle-like behavior. A crack propagates along the loading direction (i.e., perpendicular to the tensile stress created by Poisson's effect inside the sample) and cuts the sample through its height. Over the same time, it propagates along the specimen width and finally opens the sample in two parts. The spherical artificial defects intentionally added are shown to have an influence on the crack initiation, despite the presence of stress concentration zone at the interconnection between rods. The residual microporosity in the rods could not be observed with local tomography. Therefore, their role in the mechanical behavior is not known.

$\mathrm{X}$-ray tomography was used to characterize the sample at two scales. The macrostructure was imaged with a low-resolution volume whereas local tomography provided high-resolution images of the rods and especially the artificial defects. These latter images were processed to build a FE modeling having a moderate number of elements and including the presence of the artificial defects. They were included as a "second phase" different from the ceramic with a specific behavior. The maximal principal stresses obtained by this FE modeling confirm the influence of the artificial defects with an associated important stress concentration. However, other calculations implementing a more complex material behavior or with a finer mesh size would be necessary to understand better the respective role of the microstructure and the macrostructure on the scaffold's properties.

\section{Acknowledgements}

Research reported in this publication was supported by the National Institute of Dental and Craniofacial Research of the National Institutes of Health under award number 1R01DE015633 and by the French Ministry of Education and Research (grant for C. Petit $\mathrm{PhD}, 2012-2015)$. 


\section{References}

[1] M. Bohner, Calcium orthophosphates in medicine: from ceramics to calcium phosphate cements, Inter. J. Care Injured 31 (2000) SD37-SD47.

[2] R.Z. LeGeros, S. Lin, R. Rohanizadeh, D. Mijares, J.P. LeGeros, Biphasic calcium phosphate bioceramics: preparation, properties and applications, J. Mater. Sci. - Mater. Med. 14 (2003) 201-209.

[3] M. Bohner, U. Gbureck, J.E. Barralet, Technological issues for the development of more efficient calcium phosphate bone cements: A critical assessment, Biomaterials 26 (2005) 6423-6429.

[4] M. M. Stevens, Biomaterials for bone tissue engineering, Mater. Today 11 (2008) 18-25.

[5] A.J. Wagoner Johnson, B.A. Herschler, A review of the mechanical behavior of CaP and $\mathrm{CaP} /$ polymer composites for applications in bone replacement and repair, Acta Biomater. 7 (2011) 16-30.

[6] G. Daculsi, Biphasic calcium phosphate concept applied to artificial bone, implant coating and injectable bone substitute, Biomaterials 19 (1998) 1473-1478.

[7] A. Bignon, J.-J. Chouteau, J. Chevalier, G. Fantozzi, J.-P. Carret, P. Chavassieux, G. Boivin, M. Melin, D. Hartmann, Effect of micro- and macroporosity of bone substitutes on their mechanical properties and cellular response, J. Mater. Sci. - Mater. Med. 14 (2003) 1089-1097.

[8] K.A. Hing, B. Annaz, S. Saeed, P.A. Revell, T. Buckland, Microporosity enhances bioactivity of synthetic bone graft substitutes, J. Mater. Sci. - Mater. Med. 16 (2005) 467-475.

[9] S.F. Hulbert, S.J. Morrison, J.J. Klawitter, Tissue reaction to three ceramics of porous and non-porous structures, J. Biomed. Mater. Res. 6 (1972) 347-374.

[10] D.M. Liu, Influence of porosity and pore size on the compressive strength of porous hydroxyapatite ceramic, Ceram. Inter. 23 (1997) 135-139.

[11] I.H. Jo, K.H. Shin, Y.M. Soon, Y.H. Koh, J.H. Lee, H.E. Kim, Highly porous hydroxyapatite scaffolds with elongated pores using stretched polymeric sponges as novel template, Mater. Lett. 63 (2009) 1702-1704.

[12] E. Chevalier, D. Chulia, C. Pouget, M. Viana, Fabrication of porous substrates: A review of processes using pore forming agents in the biomaterial fields, J. Pharm. Sci. 97 (2008) 1135-1154.

[13] M.-K. Ahn, Y.-W. Moon, Y.-H. Koh, H.-E. Kim, Production of highly porous triphasic calcium phosphate scaffolds with excellent in vitro bioactivity using vacuum-assisted foaming of ceramic suspension (VFC) technique, Ceram. Inter., 39 (2013) 5879-5885.

[14] T. Chartier, C. Chaput, F. Doreau, M. Loiseau, Stereolithography of structural complex ceramic parts, J. Mater. Sci. 37 (2002) 3141-3147.

[15] A. Farzadi, V. Waran, M. Solati-Hashjin, Z.A. Abdul Rahman, M. Asadi, N.A. Abu Osman, Effect of layer printing delay on mechanical properties and dimensional accuracy of 3D printed porous prototypes in bone tissue engineering, Ceram. Inter., 41 (2015) 8320-8330. [16] E. Saiz, L. Gremillard, G. Menendez, P. Miranda, K. Gryn, A.P. Tomsia, Preparation of porous hydroxyapatite scaffolds, Mater. Sci. Eng. C 27 (2007) 546-550.

[17] J.G. Dellinger, J. Cesarano III, R.D. Jamison, Robotic deposition of model hydroxyapatite scaffolds with multiple architectures and multi-scale porosity for bone tissue engineering, J. Biomed. Mater. Res. A 82 (2007) 383-394.

[18] J.J. Guo, J.A. Lewis, Aggregation effects on the compressive flow properties and drying behavior of colloidal silica suspensions, J. Am. Ceram. Soc. 82 (1999) 2345-2358.

[19] J. Franco, P. Hunger, M.E. Launey, A.P. Tomsia, E. Saiz, Direct write assembly of calcium phosphate scaffolds using a water-based hydrogel Acta Biomater. 6 (2010) 218-228.

[20] J.E. Smay, J. Cesarano III, J.A. Lewis, Colloidal inks for directed assembly of 3-D 
periodic structures, Langmuir 18 (2002) 5429-5437.

[21] E.B. Duoss, M. Twardowski, J.A. Lewis, Sol-gel inks for direct-write assembly of functional oxides, Adv. Mater. 19 (2007) 3485-3489.

[22] M. Houmard, Q Fu, M. Genet, E. Saiz, A.P. Tomsia, On structural, mechanical and biodegradation properties of HA-TCP robocast scaffolds, J. Biomed. Mater. Res. B - App. Biomater. 101 (2013) 1233-1242.

[23] P. Miranda, A. Pajares, E. Saiz, A.P. Tomsia, F. Guiberteau, Mechanical properties of calcium phosphate fabricated by robocasting, J. Biomed. Mater. Res. A 85 (2007) 218-227.

[24] P. Miranda, A. Pajares, E. Saiz, A.P. Tomsia, F. Guiberteau, Fracture modes under uniaxial compression in hydroxyapatite scaffolds fabricated by robocasting, J. Biomed. Mater. Res. A 83 (2007) 646-655.

[25] E. Maire, X-Ray tomography applied to the characterization of highly porous materials, Ann. Rev. Mater. Res. 42 (2012) 7.1-7.16.

[26] C. Petit, S. Meille, E. Maire, S. Tadier, J. Adrien, Mechanical behavior of a $\beta$-TCP ceramic with a random porosity: study of the fracture path with X-ray tomography, J. Eur. Ceram. Soc. 36 (2016) 3225-3233.

[27] C. Petit, S. Meille, E. Maire, Cellular solids studied by X-ray tomography and finite element modeling - a review, J. Mater. Res. 28 (2013) 2191-2201.

[28] P. Miranda, E. Saiz, K. Gryn, A.P. Tomsia, Sintering and robocasting of $\beta$-tricalcium phosphate scaffolds for orthopaedic applications, Acta Biomater. 2 (2006) 457-466.

[29] J.-Y. Buffière, E. Maire, J. Adrien, J.-P. Masse, E. Boller, In situ experiments with X-ray tomography: an attractive tool for experimental mechanics, Exp. Mech. 50 (2010) 289-305.

[30] A.C. Kak, M. Slaney, Principles of computerized tomographic imaging. IEEE, New York, U.S.A., 1988.

[31] T. Zhang, E. Maire, J. Adrien, P.R. Onck, L. Salvo, Local tomography study of the fracture of an ERG metal foam, Adv. Eng. Mater. 15 (2013) 762-772.

[32] S. Youssef, E. Maire, R. Gaertner, Finite element modelling of the actual structure of cellular materials determined by X-ray tomography, Acta Mater. 53 (2005) 719-730.

[33] H. Toda, T. Ohgaki, K. Uesugi, M. Kobayashi, N. Kuroda, T. Kobayashi, M. Niinomi, T. Akahori, K. Makii, Y. Aruga, Quantitative assessment of microstructure and its effects on compression behavior of aluminum foams via high-resolution synchrotron X-ray tomography, Metall. Mater. Trans. A 37 (2006) 1211-1219.

[34] A. Etiemble, J. Adrien, E. Maire, H. Idrissi, D. Reyter, L. Roué, 3D morphological analysis of copper foams as current collectors for Li-ion batteries by means of X-ray tomography, Mater. Sci. Eng. B 187 (2014) 1-8.

[35] NIH National Institute of Health, Image J [in line]. Available on:

$<$ http://imagej.nih.gov/ij/ >.

[36] E. Maire, P. Colombo, J. Adrien, L. Babout, L. Biasetto, Characterization of the morphology of cellular ceramics by 3D image processing of X-ray tomography, J. Eur. Ceram. Soc. 27 (2007) 1973-1981.

[37] W.C. Oliver, G.M. Pharr, An improved technique for determining hardness and elastic modulus using load and displacement sensing indentation experiments, J. Mater. Res. 7 (1992) 1564-1583.

[38] C.X. Wang, X. Zhou, M. Wang, Influence of sintering temperatures on hardness and Young's modulus of tricalcium phosphate bioceramic by nanoindentation technique, Mater. Charact. 52 (2004) 301-307.

[39] L.-H. He, O.C. Standard, T.T. Huang, B.A. Latella, M.V. Swain, Mechanical behavior of porous hydroxyapatite, Acta Biomater. 4 (2008) 577-586.

[40] O. Caty, E. Maire, S. Youssef, R. Bouchet, Modelling the properties of closed-cell cellular materials from tomography images using finite shell elements, Acta Mater. 56 (2008) 
5524-5534.

[41] D.E. Grenoble, K.L. Dunn, J.L. Katz, R.S. Gilmore, K.L. Murty, Elastic properties of hard tissues and apatites, J. Biomed. Mater. Res. 6 (1972) 221-233.

[42] K.-T. Chu, S.-F. Ou, S.-Y. Chen, S.-Y. Chiou, H.-H. Chou, K.-L. Ou, Research of phase transformation induced biodegradable properties on hydroxyapatite and tricalcium phosphate based bioceramic, Ceram. Int. 39 (2013) 1455-1462.

[43] O. Prokopiev, I. Sevostianov, Dependence of the mechanical properties of sintered hydroxyapatite on the sintering temperature, Mater. Sci. Eng. A 431 (2006) 218-227.

[44] H.-S. Ryu, H.-J. Youn, K.S. Hong, B.-S. Chang, C.-K. Lee, S.-S. Chung, An improvement in sintering property of $\beta$-tricalcium phosphate by addition of calcium pyrophosphate, Biomaterials 23 (2002) 909-914.

[45] N. Kivrak, A. Cuneyt Tas, Synthesis of calcium hydroxyapatite-tricalcium phosphate (HA-TCP) composite bioceramic powders and their sintering behavior, J. Am. Ceram. Soc. 81 (1998) 2245-2252.

[46] G. Bruno, M. Kachanov, Porous microcracked ceramics under compression: Micromechanical model of non-linear behavior, J. Eur. Ceram. Soc. 33 (2013) 2073-2085.

[47] E.C. David, N. Brantut, A. Schubnel, R.W. Zimmerman, Sliding crack model for nonlinearity and hysteresis in the uniaxial stress-strain curve of rock, Inter. J. Rock Mech. Min. 52 (2012) 9-17.

[48] F. Pecqueux, F. Tancret, N. Payraudeau, J.-M. Bouler, Influence of microporosity and macroporosity on the mechanical properties of biphasic calcium phosphate bioceramics: modelling and experiment, J. Eur. Ceram. Soc. 30 (2010) 819-829.

[49] S. Meille, M. Lombardi, J. Chevalier, L. Montanaro, Mechanical properties of porous ceramics in compression: on the transition between elastic, brittle, and cellular behavior, J. Eur. Ceram. Soc. 32 (2012) 3959-3967.

[50] C. Petit, E. Maire, S. Meille, J. Adrien, S. Kurosu, A. Chiba, CoCrMo cellular structures made by Electron Beam Melting studied by local tomography and finite element modelling, Mater. Charact. 116 (2016) 48-54. 